\title{
Early Prediction of Plantation Performance for Red Pine
}

\author{
by
}

John M. Paterson and David C.F. Fayle ${ }^{1}$

\begin{abstract}
An indication in year 1 or 2 of the relative performance at five years of $3+0$ red pine plantations can be obtained by supplementing height and survival measurements with a quality assessment based on needle length and growth characteristics of the terminal shoot in the first two years after outplanting.
\end{abstract}

Key Words: Red pine, plantation assessment, prediction, needle length, height, survival, quality classes.

\section{Résumé}

On peut obtenir au cours de la première ou de la deuxième année une indication de la performance relative, à cinq ans, des plantations de pin rouge $3+0$ en complétant les déterminations de la hauteur et de la survie par une évaluation de la qualité d'après la longueur des aiguilles et les caractéristiques de croissance de la pousse terminale au cours des deux premières années suivant la transplantation.

Mots clés: pin rouge, évaluation des plantations, prévision, longueur des aiguilles, hauteur, survie, classes de qualité.
The early performance of red pine (Pinus resinosa Ait.) plantations is typically assessed using one or more of the following criteria (Vyse 1982): mortality, relative condition, absolute size, size increment, and a survival height index. For example, the Ontario Ministry of Natural Resources assesses plantations at the end of one and two years after planting in terms of survival, average height and a visual "quality" assessment of healthy or unhealthy; the degree and type of competition is also assessed and tending recommendations are made (Chaudry 1981).

Survival and average height are useful parameters to identify the degree of "success" a plantation has achieved to date. Quality assessment, however, can identify the potential for future growth and survival.

Here, we outline a quality assessment method that was developed for and applied to $3+0$ red pine plantations which were established to investigate the causes of poor performance in such stock after outplanting (Pierpoint et al. 1977, 1978 and 1981). The quality assessment, applied in the first and second years after outplanting, is based on the needle length and growth characteristics of the terminal shoot. The relationship of initial quality to total fifth year growth after outplanting and how this aids in the early detection of potential fifth year performance are discussed.

\section{Why Use Needle Length?}

Length of the current year's new needles in young red pine

IOntario Tree Improvement and Forest Biomass Institute, Ministry of Natura Resources, Maple, Ontario LOJ $1 \mathrm{EO}$. is an indicator of the degree of root establishment and of the next season's potential height increment and foliar development for several reasons.

Needle length is strongly affected by moisture supply (Strothmann 1967, Glerum and Pierpoint 1968, Clements 1970) which, in newly planted seedlings, will be influenced by the degree new root growth exploits the soil.

Needle elongation occurs when current shoot extension is largely completed and during the time of bud formation. The bud contains all the stem units and needle primordia for next season's shoot (Duff and Nolan 1953); the larger the bud the greater the potential height growth in the following year. Whether or not this potential is attained will depend on moisture supply during shoot extension.

Large terminal buds produce shoots with more needle fascicles than small buds (Clements 1970) and the number of lateral buds tends to increase with the number of needles on the shoot. Thus the number of branches produced and foliage mass will increase accordingly.

When excavating root systems we observed that seedlings with normal needle flush and shoot extension the first year had new growth of long and short roots over most of the root system soon after planting, whereas seedlings that remained alive with no needles flushed in the first year had localized, minimal root activity. Late flush of upper needles with no flushing of lower needles in the first year was associated with minimal early root activity followed by fairly extensive activity; new growth on original short roots remained minimal.

The proportion of needles flushed and their length at the end of the first year after outplanting indicate the degree of estab- 
lishment of a seedling. The change in needle length from first to second year is further evidence of establishment success. For example, a substantial increase in needle length suggests that a seedling is improving its degree of field establishment, whereas a short-needled, first-year seedling with minimal increase or a decrease in needle length the second year suggests that it is still poorly established.

\section{The Plantations}

In 1976 over $66003+0$ red pine from Kemptville, Midhurst and Orono nurseries were planted in six districts of the Ontario Ministry of Natural Resources: Cornwall and Tweed (Eastern Region), Lindsay and Huronia (Central Region), Algonquin Park (Algonquin Region) and Blind River (Northeastern Region). Half of the trees were handled and planted by the local district crews and the other half by a research crew. All planting was by hand on three 100 -tree plots per site per planting crew on two planting dates per site (Pierpoint et al. 1977). No chemicals were used in site preparation and no tending for competition release was performed during the next five years.

\section{Assessments}

The plantings were assessed at the end of the first, second, third and fifth growing seasons after outplanting. Each seedling was identified to ensure that successive measurements were on the same tree.

Height and Survival. Annual height increment (including last year in the nursery) and total height were measured to the nearest half centimetre on each tree. Survival, damage from insects, animals and frost, and replacement of lost terminals by lateral branches were also recorded.

Quality. In the first year, five classes were distinguished based on the length of needles on the terminal and the proportion of the terminal that had flushed needles. These needles were classified as being greater or less than $6 \mathrm{~cm}$ in length and whether they were present on more or less than two thirds of the terminal leader (Fig. 1).

In the second year, all needles flushed and they were longer than first-year needles. Therefore different length classes were used: greater than $12 \mathrm{~cm}, 8-12 \mathrm{~cm}$, and less than $8 \mathrm{~cm}$ (Fig. 2).

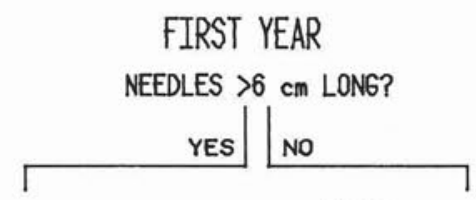

$>2 / 3$ OF TERMINAL LENGTH WITH NEEDLES FLUSHED?

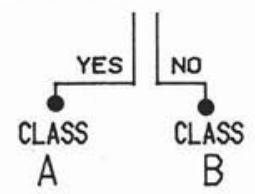

$\langle 2 / 3$ OF TERMINAL LENGTH WITH NEEDLES FLUSHED?

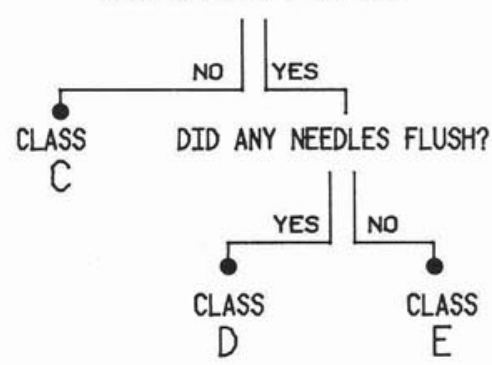

Figure 1. Key to the classification of the terminal leader of $3+0$ red pine seedlings at the end of the first year after outplanting.

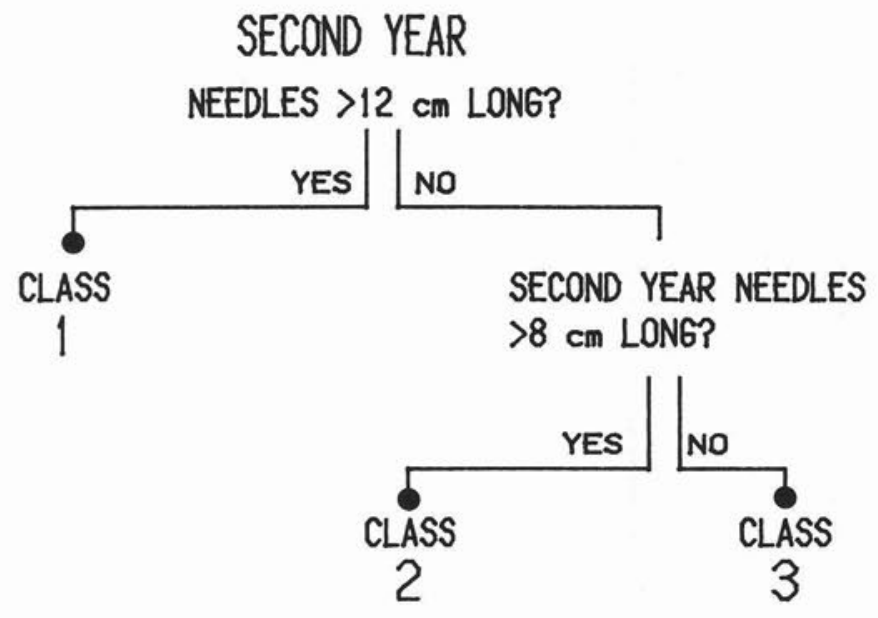

Figure 2. Key to the classification of the terminal leader of $3+0$ red pine seedlings at the end of the second year after outplanting.

\section{Analysis}

Initially, the height and survival data collected at each planting location were tested against the first- and second-year classes present at that location. All locations were then compared for homogeneity of development relative to their class.

Height growth and survival did vary between planting locations and stock origin but similarities in development relative to the initial classification remained consistent. For example, height and survival of first-year class A trees were always significantly better than of class $D$ trees, and the same applied for second-year class 1 versus class 3 trees. Since the relative ranking of classes did not differ, all data were combined to produce a more comprehensive data base for statistical comparisons.

The total combined sample of trees classified at the end of the second growing season was 6442 . At five years 5881 trees were surviving and their distribution by first- and second-year quality classes is shown in Table 1. The terminal bud of class $E$ trees frequently died and subsequent height growth was from lateral branches. For the second-year classification, the most dominant new leader was selected and its second-year needles classified, but the first-year classification for this new leader was not always recorded. Since the model relies on a continuum of growth from a previously classified leader, class $E$ trees were removed from the height growth analysis. Future assessments can be corrected to account for these growth changes in class $E$ trees.

Unless otherwise stated, the term "significant" denotes the $99 \%$ level of confidence.

Table 1. Number of trees at five years by their first- and secondyear quality classes.

\begin{tabular}{|c|c|c|c|c|}
\hline \multirow{2}{*}{$\begin{array}{l}\text { First-year } \\
\text { quality class }\end{array}$} & \multicolumn{3}{|c|}{ Second-year quality class } & \multirow[b]{2}{*}{ Total } \\
\hline & 1 & 2 & 3 & \\
\hline A & 380 & 1160 & 136 & 1676 \\
\hline B & 55 & 681 & 93 & 829 \\
\hline $\mathrm{C}$ & 97 & 1185 & 237 & 1519 \\
\hline D & 67 & 726 & 226 & 1019 \\
\hline Subtotal & 599 & 3752 & 692 & 5043 \\
\hline E & $7^{a}$ & $582^{a}$ & $249^{a}$ & 838 \\
\hline Total & 606 & 4334 & 941 & 5881 \\
\hline
\end{tabular}

which had died. (Not used in later analyses.) 
Table 2. Percent survival at five years by quality class based on surviving trees classified in year two.

\begin{tabular}{ccccc}
\hline \multirow{2}{*}{$\begin{array}{l}\text { First-year } \\
\text { class }\end{array}$} & \multicolumn{3}{c}{ Second-year class } & \\
\cline { 2 - 4 } & $\mathbf{1}$ & $\mathbf{2}$ & $\mathbf{3}$ & Total \\
\hline A & 99 & 96 & 87 & 96 \\
B & 95 & 96 & 89 & 95 \\
C & 99 & 92 & 77 & 90 \\
D & 99 & 94 & 81 & 91 \\
E & $100^{\text {a }}$ & $88^{\text {a }}$ & $73^{\text {a }}$ & 83 \\
\hline Total & 99 & 93 & 79 & 91 \\
\hline a In most cases, the second-year classification was on a lateral, not the first-year \\
terminal which had died. (Not used in later analyses.)
\end{tabular}

\section{Plantation Performance}

Fifth-year survival based on the combined first and second year quality classes is shown in Table 2. Survival was significantly lower for all second-year class 3 trees and also for second-year class 2 trees of first-year class E. Based solely on their first-year classification, class $E$ trees had a significantly lower survival than class A to D trees.

The cumulative height growth curves for five years show a significiant separation in total height in the third to fifth year based on their first-year quality class (Fig. 3) and in the second to fifth year by their second-year quality class (Fig. 4).

First-year height increment of trees whose needles did not flush on part or much of the terminal shoot (classes B and D) was significantly lower than on trees with complete needle flush (classes $A$ and $C$ ). However, when long needles developed in the first year on trees with partial needle flush (class $B)$, their height increment in the second and subsequent years was better than on those with a complete flush of short needles (class $\mathrm{C}$ ). This is shown in the cross-over of the cumulative height curves for class $B$ and $C$ trees between years one and three (Fig. 3). The longer needles of the class B trees indicated better root establishment by the end of the first year than in class $\mathrm{C}$ trees.

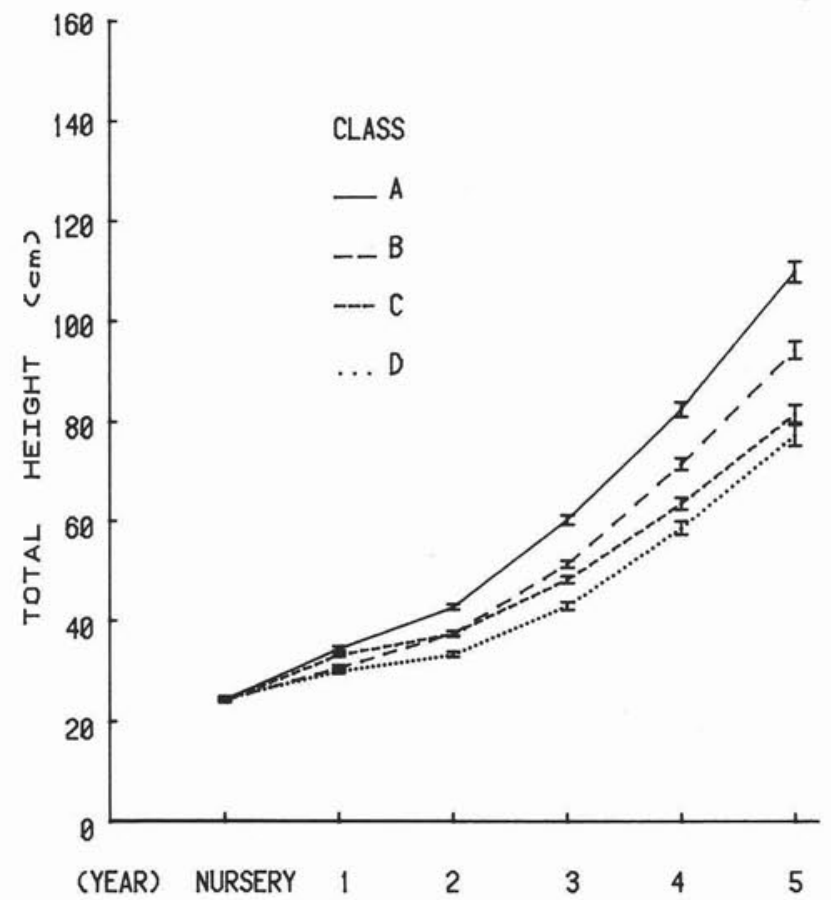

Figure 3. Mean height from the nursery and cumulative height over 5 years for trees classified in the first year after outplanting. (Vertical bar $=99 \%$ confidence interval.)

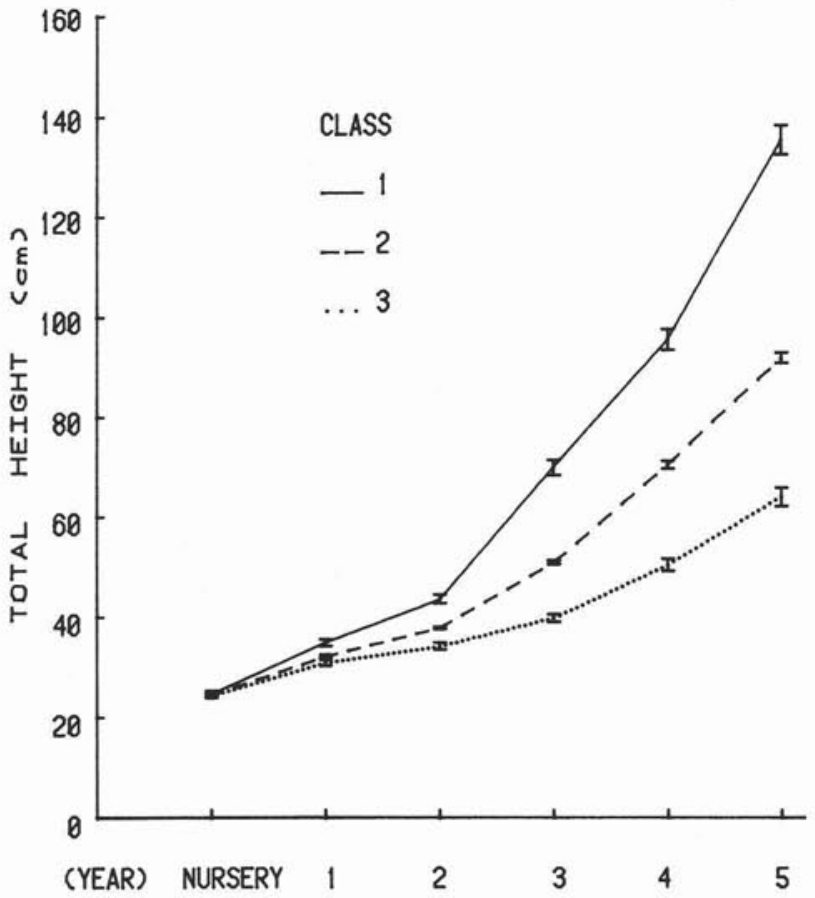

Figure 4. Mean height from the nursery and cumulative height over 5 years for trees classified in the second year after outplanting. (Vertical bar $=99 \%$ confidence interval. $)$

Although individually the first- or second-year quality classes indicate the potential growth and survival of a plantation, a more accurate assessment is provided by combining the classes. Table 3 shows the mean total heights at five years by first- and second-year quality classes, and should be examined in conjunction with Table 2.

The A1 trees were well established in year 1 and remained so in year 2, averaging $147 \mathrm{~cm}$ in height at five years (Table 3), with $99 \%$ survival (see Table 2). The A3 trees, however, were apparently established in year 1 but did not consolidate themselves in year 2, with total height and survival at five years being reduced accordingly. The D1 trees were poorly established in their first year but improved their situation in the second year. Their height and survival at five years was better than that of A3 trees and substantially better than of D3 trees which did not become established in either year.

Table 3. Fifth-year mean total height $(\mathrm{cm})$ by quality class based on surviving trees classified in year two ${ }^{a}$.

\begin{tabular}{cccc}
\hline \multirow{2}{*}{$\begin{array}{c}\text { First-year } \\
\text { class }\end{array}$} & \multicolumn{3}{c}{ Second-year class } \\
\cline { 2 - 4 } & $\mathbf{1}$ & $\mathbf{2}$ & $\mathbf{3}$ \\
\hline A & 147 & 103 & 71 \\
B & 115 & 96 & 68 \\
C & 121 & 83 & 60 \\
D & 109 & 81 & 57 \\
\hline
\end{tabular}

${ }^{a}$ Differences of $10 \mathrm{~cm}$ or more are significant at the $99 \%$ confidence interval.

\section{Benefits of Including Quality}

Various advantages accrue to the forest manager by including this quality class system with the traditional assessment methods.

Thersystem helps to discriminate between trees that are established from those that are still becoming established. Figure 5 shows the annual height increment of trees classified 


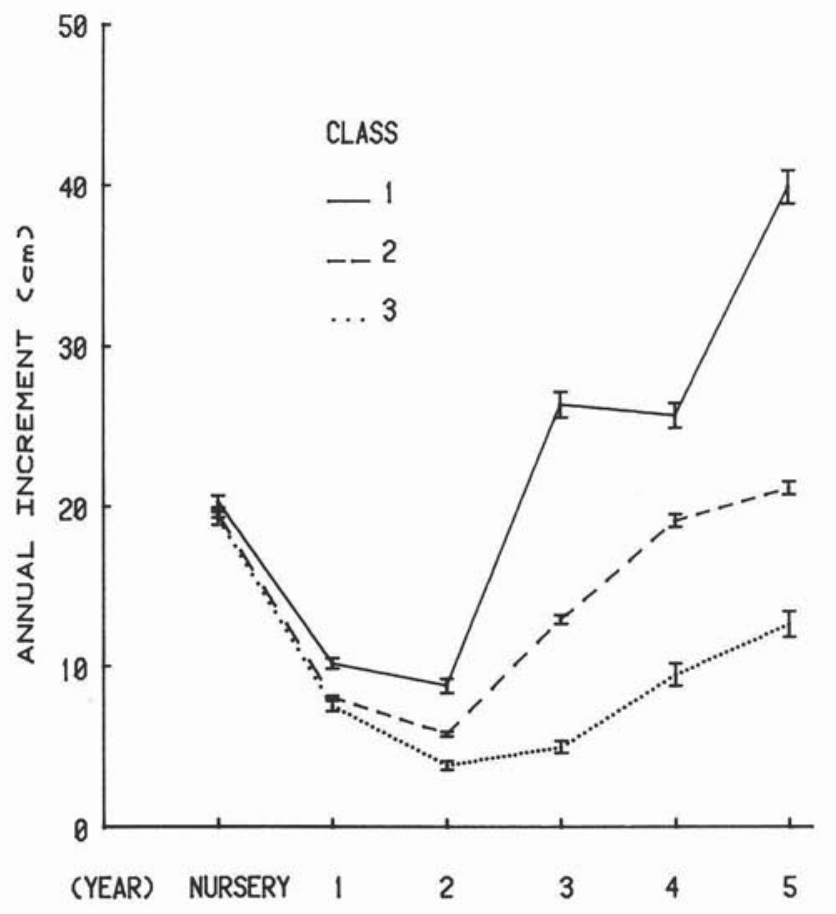

Figure 5. Annual height increment of trees based on their classification in the second year. $($ Vertical bar $=99 \%$ confidence interval.)

at the end of the second year. If we assume for $3+0$ red pine stock that a tree is established when its annual height increment is equal to or greater than its last year's nursery increment, then the class 1 trees are established in the third year, class 2 in the fourth and class 3 trees at year 5 are still not established. These delays in establishment of the class 2 and particularly class 3 trees will have long-term effects on plantation development. Poorly established trees are more likely to be adversely affected by competition and unfavorable weather. Increased management costs will be necessary to improve the establishment of such plantations.

The differences shown in Figure 5 would be accentuated if the first-year classifications were also included. Thus an A1 tree becomes established more rapidly than an $A 3$ tree. When both years are assessed, an indication is given of whether conditions are improving or not. For example, a high proportion of first-year class A or B trees shifting to second-year class 3 , leading to a reduction in total height and survival at five years, alerts the assessor to possible problems. Conversely, a high proportion of class $D$ trees moving into class 1 in the second year indicates a substantial improvement. However, if a high proportion of D3 trees occurs remedial action may be required to improve establishment.

Suppose that an assessment conducted at the end of the second year after outplanting at two separate locations shows similar height and survival at both locations, suggesting similar future development. If, however, one plantation had a high proportion of class 1 trees and the other a high proportion of class 3 trees, their performance by the fifth year would be substantially different, as indicated in Figure 4. This could not necessarily be predicted from their second-year height measurements alone.

Like Vyse $(1981,1982)$ we question the dogma of 'bigger is better' for predicting stock performance if bigger is equated with height. We divided the trees in year 2 into two height groups whose means were $31 \mathrm{~cm}$ and $46 \mathrm{~cm}$ (Fig. 6). At five

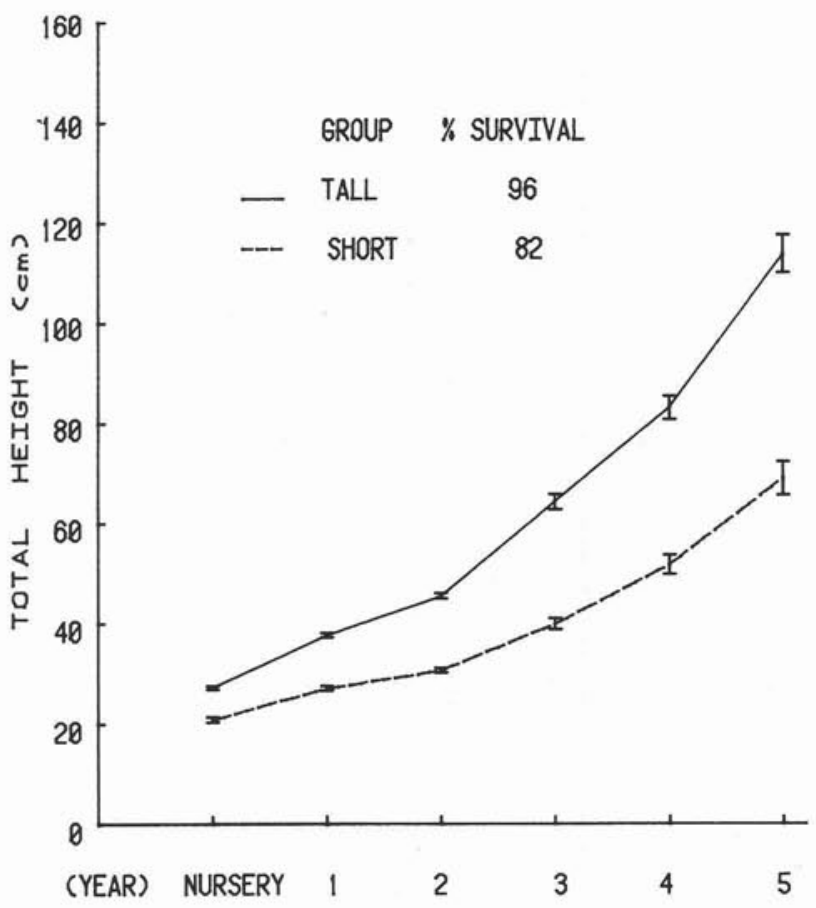

Figure 6. Mean height from the nursery, cumulative height over 5 years and survival at 5 years, based on trees above (tall) and below (short) the median height of all trees at the end of the second year. (Vertical bar $=99 \%$ confidence interval.)

years, both average total height and survival for the tall group were better than for the short group. One might conclude here that height in year 2 does indicate relative height and survival in year 5: tall trees remain tall and more survive. But this is

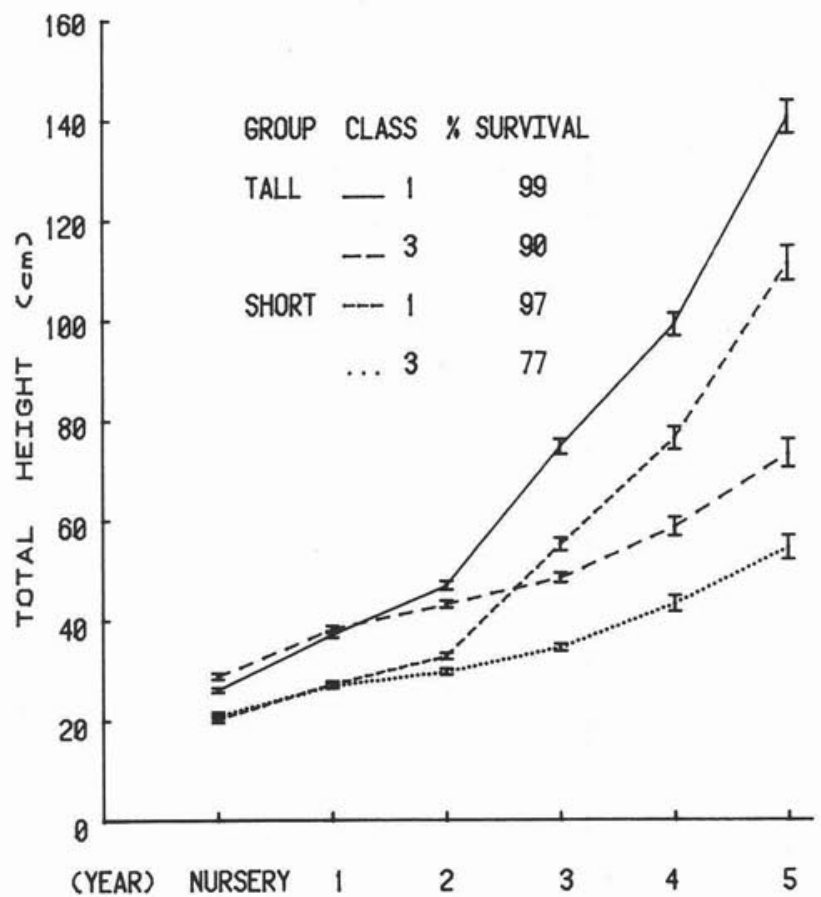

Figure 7. Mean height from the nursery, cumulative height over 5 years and survival at 5 years of the tall and short group of trees subdivided by their second year quality class. (Vertical bar $=99 \%$ confidence interval.) 
misleading and does not indicate the actual development patterns of the plantation.

The inclusion of quality classes provides a more accurate picture (Fig. 7). Class 1 trees in the short group have significantly outperformed class 3 trees of the tall group in both height and survival. A similar influence is shown in Fig. 3 where the class $C$ trees were taller than the class $B$ trees in the first year, but by year 3 they were shorter, and remained shorter.

Our results show that the pattern of plantation development in the first two years of field establishment influences future growth and survival. Recognition of and documentation of these development patterns will improve the forest manager's ability to assess the future success of a plantation at an early stage, and to take remedial action if required.

\section{Acknowledgements}

We wish to thank Don Maclver for his advice on statistical and computer analyses and also Geoff Pierpoint and Chris Glerum for establishing the original study.

\section{References}

Chaudry, M.A. 1981. Regeneration survey manual for Ontario. Ont. Min. Natur. Resour., Toronto. 76 p.
Clements, J.R. 1970. Shoot responses of young red pine to watering applied over two seasons. Can. J. Bot. 48: 75-80.

Duff, G.H. and N.J. Nolan. 1953. Growth and morphogenesis in the Canadian forest species. I. The controls of cambial and apical activity in Pinus resinosa Ait. Can. J. Bot. 31:471-513.

Glerum, C. and G. Pierpoint. 1968. The influence of soil moisture deficits on seedling growth of three coniferous species. For. Chron. 44: 26-29.

Pierpoint, G., J.M. Paterson, J.G. Boufford and C. Glerum. 1977. Irregular growth of outplanted red pine. II. The influence of handling and planting on first-year performance. Ont. Min. Natur. Resour., For. Res. Note No. 6. 4 p.

1978. Irregular growth of outplanted red pine. III. The influence of handling and planting on second-year performance. Ont. Min. Natur. Resour., For. Res. Note No. 14. 4 p.

1981. Irregular growth of outplanted red pine. VI. The influence of handling and planting on fifth-year performance. Ont. Min. Natur. Resour., For. Res. Note No. 29. 4 p.

Strothmann, R.O. 1967. The influence of light and moisture on the growth of red pine seedlings in Minnesota. For. Sci. 13: 182191.

Vyse, A. 1981. Growth of young spruce plantations in interior British Columbia. For. Chron. 57: 174-180.

Vyse, A. 1982. Field performance of small volume container-grown seedlings in the central interior of British Columbia, p. 291-297. In J.B. Scarratt, C. Glerum and C.A. Plexman (eds.). Proc. Canadian Containerized Tree Seedling Symposium. Dep. Envir., Can. For. Serv., COJFRC Sympos. Proc. 0-P-10.

\section{Ecological Services \\ for Planning Limited \\ ENVIRONMENTAL CONSULTANTS \\ - Private Forest Land Management \\ - Urban Forestry \\ - Soil, Vegetation, and Resource Inventory \\ - Slope Stabilization and Erosion Control \\ - Specialists in Forest Soil Survey and Interpretations for Management \\ 530 Willow Road-Unit 10-Guelph, Ontario-N1H 7G4 - Telephone 836-6050}

